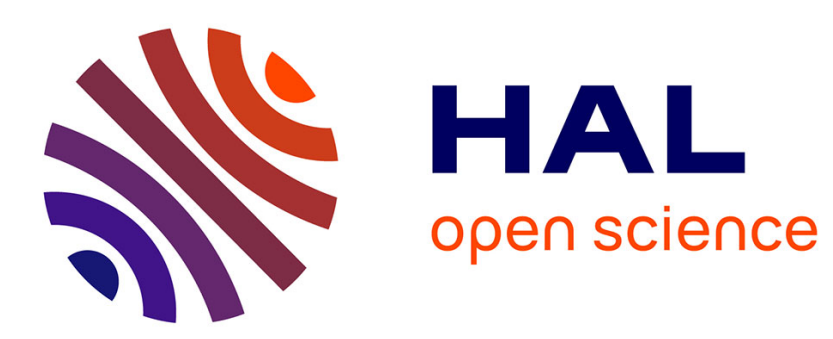

\title{
Cell Membrane Electropermeabilization
}

\author{
J. Teissie, D. Zerbib
}

\section{To cite this version:}

J. Teissie, D. Zerbib. Cell Membrane Electropermeabilization. Encyclopedia of Interfacial Chemistry, 7, pp.81-89, 2018, Surface Science and Electrochemistry. hal-01883426

\section{HAL Id: hal-01883426 https://hal.science/hal-01883426}

Submitted on 28 Sep 2018

HAL is a multi-disciplinary open access archive for the deposit and dissemination of scientific research documents, whether they are published or not. The documents may come from teaching and research institutions in France or abroad, or from public or private research centers.
L'archive ouverte pluridisciplinaire HAL, est destinée au dépôt et à la diffusion de documents scientifiques de niveau recherche, publiés ou non, émanant des établissements d'enseignement et de recherche français ou étrangers, des laboratoires publics ou privés. 


\section{Cell Membrane Electropermeabilization}

J Teissié and D Zerbib, IPBS and LISBP, University of Toulouse, CNRS, INRA, INSA, Toulouse, France

(C) 2018 Elsevier Inc. All rights reserved.

\begin{tabular}{lr}
\hline Introduction & 82 \\
Basic Technological Description of Electropulsation & 82 \\
A Biophysical Description & 82 \\
An Electric Field Has Physical Effects & 82 \\
$\quad$ Joule heating & 82 \\
$\quad$ Electrochemistry at the electrodes (pH, corrosion) & 83 \\
Electrophoresis in the suspension & 84 \\
Electrophoresis in the cell membrane & 84 \\
$\quad$ Electrical stress in the cell envelope & 84 \\
$\quad$ Stretching of the cell & 84 \\
$\quad$ Induction of acoustic shock waves & 85 \\
$\quad$ The external field induces an orientation of bacteria & 85 \\
The External Field Induces Membrane Potential Difference Modulation & 85 \\
Electropermeabilization & 86 \\
Conclusions & 87 \\
Acknowledgements & $\mathbf{8 7}$ \\
References & 88 \\
Further Reading & 89 \\
Relevant Websites & 89 \\
\hline
\end{tabular}

\section{Glossary}

Electropermeabilization Induction of transport pathways in a cell membrane by electropulsation

Electropulsation delivery of a calibrated electric pulse on a biological sample such as a bacterial suspension

Pulsed electric field Repetitive delivery of a short lived electric voltage on a conductive solution

\begin{tabular}{|c|c|}
\hline \multicolumn{2}{|c|}{ Nomenclature } \\
\hline C & Capacitor (F) \\
\hline $\mathrm{CM}$ & Cytoplasmic membrane \\
\hline$C p$ & Specific heat capacity $\left(\mathrm{J} / \mathrm{kg}^{\circ} \mathrm{C}\right)$ \\
\hline$d$ & Gap between the electrodes (m) \\
\hline$E$ & Field $(\mathrm{V} / \mathrm{m})$ \\
\hline$I$ & Current (A) \\
\hline ms & Millisecond \\
\hline$N$ & Number of repetitive pulses \\
\hline PE & Phosphatidylethanolamine \\
\hline PEF & Pulsed electric fields \\
\hline Ps & Permeability coefficient of S \\
\hline$Q$ & Charge (C) \\
\hline$R$ & Cell size $(\mathrm{m})$ \\
\hline$T$ & Pulse duration (sec) \\
\hline TEM & Transmission electron microscopy \\
\hline TMP & Transmembrane potential \\
\hline$V$ & Voltage (V) \\
\hline$W$ & Energy (J) \\
\hline$\Delta \theta$ & temperature increase $\left({ }^{\circ} \mathrm{C}\right)$ \\
\hline$\Delta \Psi_{\mathbf{l}}$ & TMP induced by the electric field (V) \\
\hline$\lambda s$ & Buffer conductivity (S/m) \\
\hline
\end{tabular}




\section{Introduction}

Since the pioneering results describing electropermeabilization of microorganisms published 50 years ago, ${ }^{1-3}$ there has been a lot of interest in the translational developments of these observations. One of the problems limiting industrial development of this technique is our extremely limited knowledge of the physicochemical mechanisms supporting the reorganization of the cell membrane and bacterial wall. Electropermeabilization is more than simply punching holes in a one lipid bilayer as assumed in the early versions of "electroporation." 4,5

Many poorly characterized electrochemical events are associated with the delivery of electric pulses on an ionic suspension. The physiology of the bacteria controls many parameters. This is indeed very complex in microbiology. The associated destabilization of the membrane's selective permeability is stressful for the cells and results in a loss of cell viability. Events occur at the level of the plasma membrane (as observed mostly with mammalian cells) but with a control and/or feedback on the cell envelope organization.

This article will present a description of our present knowledge on the effects linked to the application of an electrical field (i.e. current) on a cell in suspension and the way they control the alteration of the membrane.

\section{Basic Technological Description of Electropulsation}

Pulsed electric fields (PEF) are obtained by delivering a controlled voltage V between a set of two electrodes during a short duration. The field $E$ is

$$
E=-\operatorname{grad}(V)
$$

from the Maxwell equations.

When the electrodes are flat and parallel, the field is

$$
E=V / d
$$

where $d$ is the gap between the electrodes. A more complex definition is present when more sophisticated electrode geometries are selected. A nonhomogeneous field distribution is present. ${ }^{6-8}$

The voltage is either constant during the pulse duration $(T)$ (square wave) or exponentially decays (capacitor discharge system) with a characteristic decay constant $\tau C$ that is dependent upon the charge storage capacitor $(C)$ and the load $R$ (the suspension between the electrodes).

$$
\tau C=R C
$$

Rise times are always short (less than $1 \mu \mathrm{s}$ ) in comparison with the total duration of the pulse.

One technical difficulty with square wave pulse is that the voltage is observed to decrease during the pulse delivery. To limit this problem, the current $I$ should remain limited to be sure that the charge $Q$ that is delivered during the pulse duration $T$ remains small as compared to the global electrical charge stored in the pulse generator.

$$
Q=I T
$$

As the microbial suspension's electrical characteristics change during the voltage delivery, a small resistor is placed parallel to the pathway across the electrodes. The load between the electrodes where the bacterial suspension is present is much larger and has a minor contribution to the impedance of the system where the generator delivers its charge.

In most applications, a train of repetitive pulses is delivered on the suspension. Each single pulse in the train can be similar and one more parameter should be given: the delay between each (or the frequency). The pulse in a train can be either monopolar or bipolar. In the last case, two delays may be described as the train may be the application of successive pairs of bipolar pulses (with a short delay) with a longer delay between each pair.

The energy $W$ that is delivered to the sample during the train of $N$ pulses is

$$
W=\mathrm{UINT}
$$

It is mostly converted into heat. It requested that the power supply associated with the pulse generator would be suited for such energy storage.

\section{A Biophysical Description}

\section{An Electric Field Has Physical Effects}

Physicochemical effects of electrical pulses are complex as contributions are of both physical and electrochemical nature.

\section{Joule heating}

An obvious effect of the current passing through the suspension is the associated Joule heating. This is dependent on many parameters. Under the assumption that the field is generated by the application of a voltage between two flat parallel electrodes 
(to get a homogeneous field), the associated temperature increase $\Delta \theta$ for a single pulse (at given field constant $E$ and duration $T$ ), is dependent on the buffer conductivity $\lambda$ s and of course on the specific heat capacity $C p$.

$$
\Delta \theta=E^{2} T \lambda s / C p
$$

When a train of successive pulses is delivered, as long as no heat dissipation occurs in the inter-pulse delay, a linear increase in temperature should be present with the number of repetitive pulses $N$

$$
\Delta \theta_{\mathrm{N}}=E^{2} T N \lambda s / C p
$$

Indeed, when the inter-pulse delay is increased, the temperature increase is observed to be less than with a linear prediction.

This must be corrected by the change in the buffer conductivity with the temperature.

$$
\lambda s(\theta 0+\Delta \theta)=\lambda s(\theta 0)(1+\alpha \Delta \theta)
$$

A higher increase than predicted by the linear relationship on the pulse duration is present.

Another prediction is that the temperature increase in the suspension will depend on the buffer conductivity (within a single pulse or during a train of repetitive pulses). A higher effect should occur in the $1 \mathrm{mS} / \mathrm{cm}$ solution $(5 \mathrm{mM} \mathrm{NaCl})\left(\mathrm{about} 10^{\circ} \mathrm{C}\right.$ after 250 pulses $7.5 \mathrm{kV} / \mathrm{cm}, 5 \mu \mathrm{s}$ assuming no cooling during the inter-pulse delay of $1 \mathrm{~ms}$, $\rho$ s being assumed to be constant), but only $2^{\circ} \mathrm{C}$ in a $0.2 \mathrm{mS} / \mathrm{cm}$ solution $(1 \mathrm{mM} \mathrm{NaCl}$ ) (same other pulsing parameters) and negligible in a very low conductivity buffer (less than $0.1 \mathrm{mS} / \mathrm{cm}$ ) such as double-distilled water. This thermal effect should be taken into account in electropulsation effects; for example, it was reported that bacterial eradication associated with PEF was strongly positively dependent on the solution temperature. $^{9-12}$

One problem with the Joule heating associated with PEF is the heterogeneity of the field distribution in the pulsing chamber when a sophisticated geometry is selected (co-axial design). "Hot spots" are present at the sites where a high field is present.

This problem of temperature control is crucial when treating bacteria because they are physiologically sensitive to excessive temperatures (say larger than $60^{\circ} \mathrm{C}$ ) even during a short period. ${ }^{13,14}$

\section{Electrochemistry at the electrodes ( $\mathrm{pH}$, corrosion)}

Delivering a voltage between two electrodes on a conductive liquid is associated with many electrochemical reactions at the metalsolution interface.

A specific feature in a PEF system is that the current densities $\left(\mathrm{A} / \mathrm{cm}^{2}\right)$ at the electrodes are orders of magnitudes larger than in traditional electrochemical systems. Large currents are delivered across the electrode-liquid interface in a PEF treatment chamber. These currents result in electrochemical reactions along the electrode surface on a large scale. An in-depth study was published. ${ }^{15}$

Electrode reactions are shown to induce changes in the chemical structure of the liquids in the vicinity of the electrode surfaces, and can produce toxic chemicals such as reactive oxygen species (ROS). These reaction products then react with other compounds present in the solution. Such critical postpulse reactions are a secondary reaction of chlorine and water, with the formation of hydrochloric acid and hypoclorous acid. Electropulsed solutions where chlorine is present are toxic even long after pulse delivery. PEF-associated electrochemistry in the solution is complex, as it induces a cascade of reactions with both short-term and long-term biological consequences.

Theoretical predictions of ion transport in agar gels during voltage delivery mimicking PEF conditions predict the presence of pH fronts emerging from both electrodes. ${ }^{16-18}$ Experimental measurements by direct optical methods based on pH-sensitive dyes, followed by digital image processing, show that those $\mathrm{pH}$ fronts are present, immediate, and substantial. It is found that they spread by a predominantly diffusive process. The movement of the $\mathrm{pH}$ fronts depends on electrical conductivity, ion strength, and $\mathrm{pH}$ of the solution. No pH change is observed when PEF is delivered on a saline-buffer (PBS) that is able to compensate occurring pH changes. The PEF effects are therefore controlled by the composition of the bacterial solution and its buffering properties. In nonbuffered conditions (waste water, juice), pH-shifts of more than four units are predicted and observed as a result of a treatment time of shorter than ms at electric field strength of $10 \mathrm{kV} / \mathrm{cm}$. This means that $\mathrm{pH}$ values as different as 10.9 and 3.3 are detected at the cathode and anode respectively after PEF treatment of a pure salt solution with an initial non buffered pH value of 7.1. Understanding of PEF global effects on a bacterial suspension should include the potent contributions of electrochemical reactions and $\mathrm{pH}$ changes associated to the treatments. By a proper choice of pulsing and solution conditions where the potentially deleterious effects of electrical pulses on temperature and $\mathrm{pH}$ are avoided, PEF can be used appears for bacterial control of drugs in solution by keeping the pharmaceutical value of the drug unaffected. ${ }^{19}$

For assessing modifications caused by pulsed electric fields due to occurrence of electrochemical reactions at the electrode/electrolyte interface, the cell environment was investigated using electrochemical impedance spectroscopy (EIS). Analyzing the impedance of the system on a wide frequency range as EIS does allow distinguishing the complexities of the electrochemical reactions taking place, to identify diffusion-limited reactions, and analyze the capacitive behavior of the sample. Pulsed electric fields affect the electrode state under the control of the different electrolyte conductivities at the interface. ${ }^{20}$ The electrochemical reaction rate is both a function of the initial free charges and those associated with the pulsed electric field. In the presence of biological cells, the initial free charges in the medium are reduced. The PEF consequences are clearly controlled by the buffer conductivity.

A main effect on the electrodes associated with PEF is their corrosion. ${ }^{15}$ This is a well-known electrochemical reaction present at the metal solution interface when a current is delivered. Again, it should be pointed out that the current densities present on the 
electrode surface are orders of magnitudes larger than in traditional electrochemical systems. This corrosion can seriously damage the electrodes within a few hours, as observed with industrial-scaled processes. This is controlled by the current crossing the electrode solution interface, that is, the applied voltage and the solution conductivity. Depending on operational parameters, the effect may be limited, but remains present and is part of the PEF mediated reactions. This was shown to be dependent on the nature of the electrodes. Stainless steel and aluminum electrodes are observed to be highly sensitive to this corrosion effect. Iron (or aluminum) ions are present in the suspension after its PEF treatment. ${ }^{21-23}$ Food processing may be affected due to the associated toxicity problems, limiting the practical use of electroeradication. ${ }^{24}$ The electrochemical reactions associated with corrosion are dependent on the chemical composition of the bacterial suspension and the electrical parameters. ${ }^{15,24,25}$ The timedependent alteration of the electrodes is adding some more complexity in the processes associated to the PEF treatment of bacteria. A dramatic effect is the change in the surface aspect of the electrodes and their interfacial electric properties. ${ }^{26}$ Local "hot spots" of the field distribution may appear, resulting in change in the impedance of the pulsing chamber and justifying the need to follow it on-line (by recording both the delivered current and voltage).

The release of iron or aluminum ions in the pulsed suspension may have dramatic effects, as it can cause the formation of insoluble aggregates. The free concentration of added components of the solution would be altered in a dramatic way. ${ }^{27}$ This affects the dose-dependence of their effect.

Different approaches have been proposed to limit the contribution of the corrosion to the PEF processes. Different compositions of the electrodes were positively tested using other metals when building the electrodes ${ }^{28}$ including the use of cuvettes with conductive polymer electrodes. ${ }^{15,27}$ Modification of the pulsing buffer composition resulted in positive effects, such as addition of EDTA or the use of an acidic citrate electroporation buffer. But there is a need to ensure that these additives are not affecting the bacterial envelope. Interestingly, it was suggested that using bipolar pulses prevents these electrochemical effects if the delay for polarity inversion is short enough.

\section{Electrophoresis in the suspension}

Bacteria have a surface charge that makes them sensitive to an electrophoretic drift when submitted to an electric field. The associated movement pushes the bacteria along the field direction and results in accumulation on one of the electrode surfaces. Fouling is caused by the formation of a film adjacent to the treatment electrode, which can cause local electric field distortion and arcing. This agglomeration of the fouling agent on the electrode(s) during extended processing periods can cause electrical breakdown in the treatment chamber, fouling, or contamination of the system.

\section{Electrophoresis in the cell membrane}

Some membrane components are freely mobile in the cell membrane (glycolipids, proteins) as part of the fluidity of the cell membrane matrix. As their polar groups in the external solution are highly charged, as in the case of glycosylated derivatives, a force is present when the external field is present. An electrophoretically driven lateral movement is triggered when the external field pulse is delivered. As a result of this lateral movement along the electric field lines, an accumulation of the affected molecules towards one pole of the cell will result. ${ }^{29-31}$ This affects the distribution of the molecules in the membrane matrix and brings the formation of charged domains. Noncovalently bound components of the cell wall are affected. This is obvious in the case of the outer membrane.

The drift velocity is under the control of the applied field. The length of the displacement depends on the pulse duration and on the membrane and wall viscosities (that are difficult to evaluate).

\section{Electrical stress in the cell envelope}

Polar headgroups of lipids in biological membranes are dipoles that are affected by the local electrical charges. They are called "interfacial electrometers." The influence of the field on the molecular structure was monitored in the phosphatidylcholine headgroups. The conformation of the headgroups was greatly affected while no influence on the structure and dynamics of the hydrocarbon chains could be detected. The field directly affects the polar head region in membrane by inducing a tilt in its average orientation. ${ }^{32}$ Affecting the hydration forces (local structuration of the interfacial water) would result in a dramatic change in the membrane interfacial properties. ${ }^{33}$

Electrically charged macromolecules (teichoic acids) are present in the cell wall. They were shown to affect the wall organization during the PEF delivery. The repulsion between teichoic acids is affected by the drift of ions induced by the external field (bulk electrophoresis). Free ions interacting with the teichoic acids to minimize their repulsion would leave the bacterial wall, unmasking the negative charges of teichoic acids. This could increase the repulsion between them. As those charged macromolecules are embedded in a peptidoglycan gel, this increase in their repulsion would result in the creation of a very high mechanical tension in the gel. When the tension reached a critical value, the peptidoglycan gel would locally rupture, resulting in an increase in the wall porosity. ${ }^{34}$

\section{Stretching of the cell}

In the presence of electric fields, vesicles are deformed, because of an electric stress brought by the external electric field on the membrane (considered as a dielectric flexible sheet such as a lipid bilayer). It is given by the Maxwell stress tensor. The theory behind the effect of a square wave pulse was described more than 20 years ago. ${ }^{35,36}$ Stretching the pulsed cells under electric Maxwell stress will result in vesicle elongation. At a nanoscale level of the membrane, smoothing of thermal undulations is present. ${ }^{37}$ At a larger scale, shape changes from a sphere to ellipsoid deformation or an elongation of the rod are predicted or observed with highly flexible lipid vesicles. ${ }^{38}$ This was systematically investigated in the case of giant unilamellar vesicles (cell 
size like) (GUV) under electrical conditions rather similar to those of PEF treatments. Due to the high elasticity of the lipid matrix, the deformations were present only during the field application (less than $1 \mathrm{~ms})\left({ }^{39,40}\right)$. A cell envelope has properties of both elasticity and viscosity. A cell membrane is connected to the cytoskeleton and or the cell wall. Its mechanical properties are complex and should be described as a complex assembly of a Maxwell material and a Kelvin-Voigt material. This means that the deformations under a mechanical stress (as induced by the electric field) are not as in the case of elastic materials. Deformations are dependent upon the level of the stress and on its duration. ${ }^{41}$ Irreversible deformations may result and when a small stress is present for a sufficiently long duration, irreversible strains enlarge and a dramatic elongation affects the cell assembly. The resulting consequences on cell organization are dependent on the field pulse conditions (duration, strength, repetition).

The deformation is associated with a gradient of electrical conductivities between the external buffer and the internal content of the vesicle. Such a gradient is present under PEF conditions where a buffer of low conductivity is used to reduce the Joule heating and the energy costs. The cytoplasmic ionic content of bacteria is known to be high. Experiments on GUV showed that the deformation was controlled by both the field strength and the pulse duration. Indeed long ( $\mathrm{ms})$ pulses can induce a rupture of the lipid matrix and a partial fragmentation of the vesicle (resulting in a reduction in their size). ${ }^{42}$

\section{Induction of acoustic shock waves}

PEF mediates nonelectrical factors, such as pressure transients, that bring external mechanical stress on the cell membrane. Pressure transients can result in inertial cavitation shock waves. Such disruptive effects are present as observed by the fragmentation of lipid vesicles. ${ }^{43}$ A more direct observation of the high frequency pressure transient is obtained by optical methods such as the probe beam deflection technique. ${ }^{44}$ A linear dependence of the pressure wave magnitude on the applied voltage (governing the local field magnitude) is present also as a more complicated effect of the pulse duration.

\section{The external field induces an orientation of bacteria}

A field-induced orientation phenomenon is affecting the rod-shaped Escherichia coli bacteria during the pulse. The Orientation of a rod in an electric field is predicted to be due to the induction of dipoles (with a dipolar moment linearly dependent on the field) at the cell surface followed by the orientation of these dipoles. The orientation process brings the cell parallel to the field direction (torque effect of the field on the induced dipole). The pulse duration must be longer than the orientation characteristic time (approximately $1 \mathrm{~ms}$ ) to obtain a full orientation. The kinetic constant of the orientation (resulting of the effect of a field on the field induced dipole) is dependent upon the square of the field magnitude.

Direct video observation shows that the random distribution of the bacterial population changes to a well-ordered distribution just after the pulse (the time resolution, $40 \mathrm{~ms}$, is much longer than the pulse duration, but several orders of magnitude shorter than the relaxation process induced by Brownian motion. ${ }^{45,46}$ ). During the pulse, the long axis of bacteria draws parallel to the field lines. As observed by video monitoring, the field pulse causes rod-shaped bacteria to orient parallel to the field lines. Rapid kinetic turbidity changes indicate that this process happens quickly. An electric field applied to a nonspherical-cell suspension affects the optical anisotropy which can be measured by light transmission with a high temporal resolution. ${ }^{47}$ An increase in transmitted light is detected during the pulse in agreement with the uniform alignment of bacteria along the field lines observed by the direct video monitoring. At $E>2 \mathrm{kV} / \mathrm{cm}$, the orientation process occurs with a plateau value of the half-life shorter than $1 \mathrm{~ms}$, that is, in the range of the PEF cumulated duration or shorter. The conclusion is that during a pulse application longer than 1 ms, the field is most of the time applied to a bacterial population in which all the rods are parallel to the field lines. When high fields are used with a very short duration (as in the case of bacterial eradication), such an orientation results due to the cumulative effect of successive pulses delivered at a high frequency (Fig. 1).

\section{The External Field Induces Membrane Potential Difference Modulation}

An external electric field modulates the transmembrane potential (TMP) as a cell can be considered as a spherical capacitor. ${ }^{48}$ The TMP induced by the electric field after a (capacitive) charging time, $\Delta \Psi i$, is a complex function $g(\lambda)$ of the specific conductivities of the membrane $(\lambda \mathrm{m})$, the pulsing buffer $(\lambda o)$ and the cytoplasm $(\lambda i)$, the membrane thickness, the cell size $(r)$, and packing. Thus, when assuming that a cell is a sphere:

$$
\Delta \Psi_{i}=f \cdot g(\lambda) \cdot r \cdot E \cdot \cos \theta(1-\exp (-t / \tau m))
$$

in which $\theta$ designates the angle between the direction of the normal to the membrane at the considered point on the cell surface and the field direction, $E$ the field intensity, $r$ the radius of the cell and $f$, a shape factor (a cell being a spheroid). Therefore, $\Delta \Psi_{1}$ is not uniform on the cell surface. It is maximal at the positions of the cell facing the electrodes. The last term is telling that the TMP steady value is obtained only after a charging period $\tau m$. $\tau m$ is dependent on the cell size $r$ and on the external buffer conductivity. The associated loading time is strongly dependent on the external conductivity $\lambda c$.

$$
\tau m=r \operatorname{Cmem} \operatorname{br}(\lambda c+2 \lambda o) /(2 \lambda c \lambda o)
$$

A decrease in the charging time of TMP occurs with an increase in the external solution conductivity.

Another factor affecting the induced potential differences is the shape of the cell and their relative orientation to the field lines. ${ }^{49}$ This is of course very important in the case of rod shaped bacteria. One should take into account that following the orientation of the bacteria (a rod) relative to the field (homogeneous with a parallel plate electrode pulsing chamber), two limit charging times are 

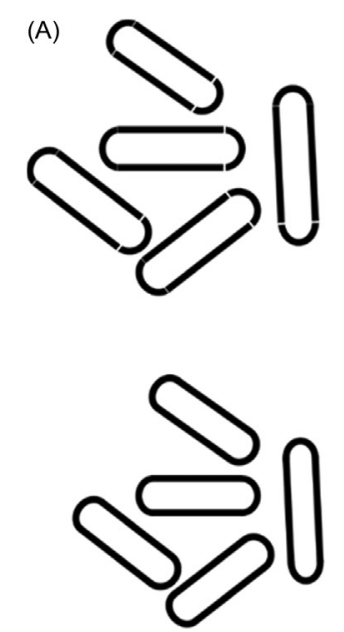

(B)
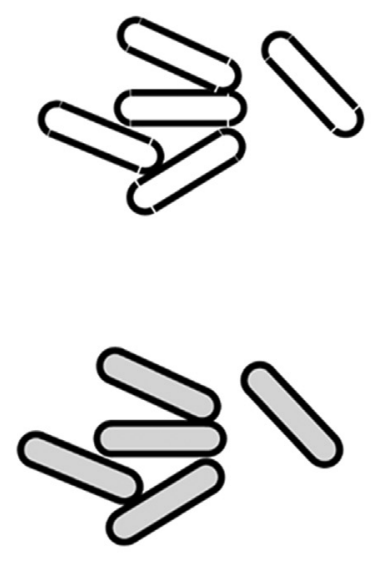

(C)
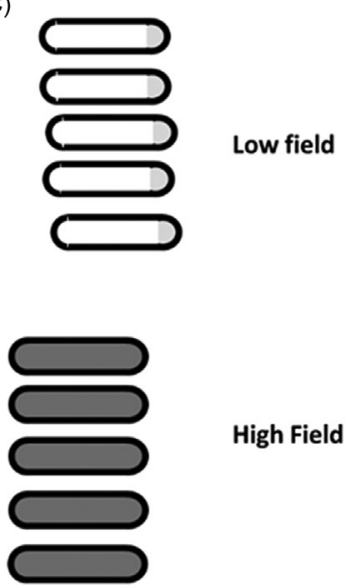

High Field

Fig. 1 Change in orientation and induction of permeabilization of rod shaped bacteria. (A) Before the pulse delivery, the orientation of each bacterium in the population is random. (B) During the pulse train, an orientation parallel to the field is induced with the same kinetic. Permeabilization is present only under the high field condition and affects all the surface of the bacteria (low grey). (C) After the pulse train, all bacteria are oriented parallel to the field. Permeabilization is present at a high level (dark grey) all over the surface under the high field condition, while only a cap is affected under the low field condition (low grey).

present (two different values of $r$ ). This charging time was calculated to be long (17-50 $\mu \mathrm{s}$ ) in a very low conductivity buffer ( $3 \mu \mathrm{S} /$ $\mathrm{cm})$. However, with more classical buffers $(0.2 \mathrm{mS} / \mathrm{cm}$ and $1 \mathrm{mS} / \mathrm{cm})$, both $\tau \mathrm{m}$ are as short as $1 \mu \mathrm{s}$, meaning that the steady state TMP should be reached during the pulse and would be present during a large part of a single pulse duration. ${ }^{50,51}$

\section{Electropermeabilization}

When the resulting transmembrane potential difference $\Delta \Psi$ (i.e., the sum between the resting value of cell membrane $\Delta \Psi o$ and the electroinduced value $\Delta \Psi i$ ) reaches locally more than $250 \mathrm{mV}$, that part of the membrane becomes permeable for small charged molecules.

Permeabilization is controlled by the field strength. Field intensity larger than a critical value $\left(E_{p, r}\right)$ must be applied to the cell suspension. From Eq. (1), in the case of a spherical cell, permeabilization is first obtained for $\theta$ close to 0 or $\pi$. $E_{p, r}$ is such that:

$$
\Delta \Psi_{i, \mathrm{perm}}=f \cdot g(\lambda) \cdot r \cdot E_{p, r}
$$

Permeabilization is therefore a local process on the cell surface. The extend of the permeabilized surface of a spherical cell, $A_{\text {perm, }}$ is given by:

$$
A_{\text {perm }}=A_{\text {tot }} \frac{\left(1-\frac{E_{p, r}}{E}\right)}{2}
$$

where $A_{\text {tot }}$ is the cell surface and $E$ is the applied field intensity. Increasing the field strength will increase the part of the cell surface, which is brought to the electropermeabilized state (Fig. 2).

These theoretical predictions are experimentally directly supported on cell suspension by measuring the leakage of metabolites (ATP) ${ }^{52}$ Electrophoretic forces during the pulse may contribute but most of the transport occurs after the pulse. Leakage results from a concentration driven diffusion transport described by using the Fick equation on the cell electropermeabilized part. The permeabilized part of the cell surface is a linear function of the reciprocal of the field intensity. This gives the following expression in the case of a spherical cell for a given molecule $S$ and a cell with a radius $r$ pulsed under reversible conditions:

$$
\phi(S, t)=2 \pi r^{2} \cdot P_{S} \cdot \Delta S \cdot X(N, T)\left(1-\frac{E_{p, r}}{E}\right) \exp (-k \cdot(N, T) \cdot t)
$$

where $\Phi(S, t)$ is the flow at time $t$ after the $N$ pulses of duration $T$ (the delay between the pulses being short compared to $t$ ), $P_{\mathrm{s}}$ is the permeability coefficient of $S$ across the permeabilized membrane and $\Delta S$ is the concentration difference of $S$ across the membrane. It is important to observe that electropermeabilization quantification is assayed by the associated transport (diffusion) of a given $S$ molecule and therefore depends on this molecule. $E_{\mathrm{p}}$ depends on $r$ (size). Under low-conductivity conditions, the electric stretching force contributes significantly to the increase in "electroleaks" across the plasma membrane, that is, in $P_{s} .{ }^{53}$ The last term is reflecting the resealing. 
(A)

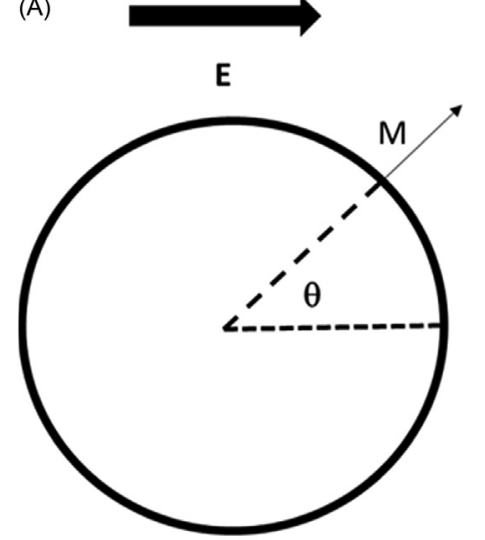

(B)

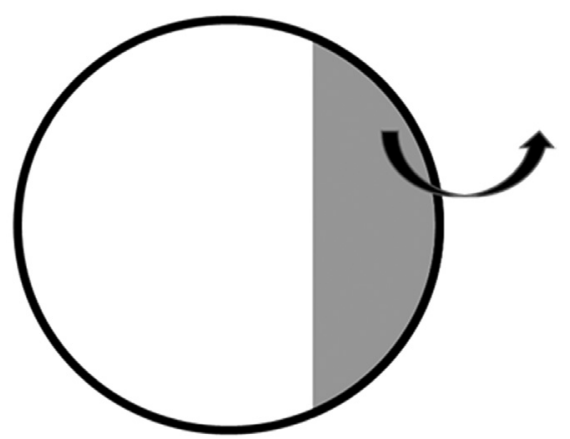

Fig. 2 (A) TMP(M) is a function of $E$ and $\theta$, (B) The grey area is the part of the cell surface where the induced TMP is larger than the critical permeabilizing value, $A_{\text {perm. }}$. It is controlled by the applied field $\left(E>E_{p}\right)$. Diffusion (arrow) occurs across this part of the cell surface after the pulse.

The area affected by the electric field depends also on the shape (spheroid) and on the orientation of the cell with the electric field lines. With ms long pulses, only the caps of the oriented rod facing the electrodes will be affected. When strong field pulses ( $>20 \mathrm{kV} /$ $\mathrm{cm}$ ) are delivered, a more global damaging effect is present.

Experimental results obtained either by monitoring conductance changes on cell suspension ${ }^{54}$ or by observation of the leakage of metabolites show that the density of the local alterations is strongly controlled by the pulse duration. Delivery of a train of successive pulses, as an increase of their number results, leads to an increase of local permeabilization level.

Electropermeabilization of the cell membrane is a multistep process occuring on different time scales:

1. Induction step (ns). The electric field induces a membrane potential difference increase. When it reaches a critical value (about $200 \mathrm{mV})$, local "defects" appear.

2. Expansion step $(\mu \mathrm{s})$. Defects expend and new defects appear as long as the field above the critical value is present. A high conductivity is present across the membrane.

3. Stabilization step (ms). As soon as the field intensity is lower than the critical value, a recovery process takes place within a few milliseconds, which brings the membrane to the "permeabilized state" with a low but significant conductivity.

4. Resealing step (s, min). A slow resealing of the defaults occurs. The membrane conductivity decreases back to its prepulse value.

5. Memory effect (h). Some changes in the membrane properties remain present on a longer time scale, but the cell behavior returns to normal.

Electropermeabilization can be irreversible or reversible. The five steps are relevant to a reversible permeabilization that is used when the cell viability should be preserved. This is the case for gene transfer where the expression of the coded activity is required or for the bacterial genome editing. Information on the events affecting the wall to support the transfer of the macromolecular nucleic acid are missing except the ultrastructural details that are obtained long after the pulse. ${ }^{55,55-59}$

But, with a proper choice in pulsing conditions, Step 4 can be eliminated. Permeabilization is therefore irreversible. Cell viability is not preserved as expected for bacterial eradication.

\section{Conclusions}

PEF appears to be a promising, environmentally-friendly, cost-effective technology for use in the biotechnological industry and for potentially impressive application in clinics (solid tumor eradication by electrochemotherapy, DNA Vaccine). Optimization of the processes has been studied using empirical approaches in different groups in the United States and in Western Europe. This limits the availability of industrial devices on the market. But in order for industry to take full advantage of the methodology, there must be more basic investigation into the biophysical processes supporting the membrane alterations in treated microorganisms.

Cells are more than a vesicle with a dielectric shell. One should consider the different effects associated with the train of electric pulses and how they may be controlled through manipulation of the electric parameters (field strength, pulse duration, delay between the pulse). Another critical factor is the organization of the cell envelope and its complex response not only to the physical (electromechanical) constraints, but also to metabolic stress associated with the high-level membrane electropermeabilization.

\section{Acknowledgements}

This work was supported by the European FP7 (Electroextraction, [FP7-SME-2007-1], Grant Agreement No. 222220) Projects. Research was conducted in the scope of the EBAM European Associated Laboratory (LEA) and resulted from the networking efforts of the COST Action TD1104 (http:// www.electroporation.net). 
See also: Ion Channel Formation in Bilayer Lipid Membranes; Ion Conductance Probe Microscopy—Molecular Resolution; Thylakoid Membrane Bioenergetics.

\section{References}

1. Hamilton, W. A.; Sale, A. J. H. Effects of High Electric Fields on Microorganisms. II. Killing of Bacteria and Yeasts. Biochim. Biophys. Acta 1967, 148, 789-800. https:// doi.org/10.1016/0304-4165(67)90053-0.

2. Sale, A. J. H.; Hamilton, W. A. Effects of High Electric Fields on Microorganisms: I. Killing of Bacteria and Yeasts. Biochim. Biophys. Acta 1967, 148 (3), 781-788. https:// doi.org/10.1016/0304-4165(67)90052-9.

3. Sale, A. J. H.; Hamilton, W. A. Effects of High Electric Fields on Micro-Organisms: III. Lysis of Erythrocytes and Protoplasts. Biochim. Biophys. Acta 1968, 163, 37-43. https://doi.org/10.1016/0005-2736(68)90030-8.

4. Barnett, A.; Weaver, J. C. Electroporation: A Unified, Quantitative Theory of Reversible Electrical Breakdown and Mechanical Rupture in Artificial Planar Bilayer Membrane. Bioelectrochem. Bioenerget. 1991, 25, 163-182. https://doi.org/10.1016/0302-4598(91)87001-W.

5. Weaver, J. C.; Chizmadzhev Yu, A. Theory of Electroporation: A Review. Bioelectrochem. Bioenerget. 1996, 41, 135-216.

6. Fiala, A.; Wouters, P. C.; van den Bosch, E.; Creyghton, Y. L. M. Coupled Electrical-Fluid Model of Pulsed Electric Field Treatment in a Model Food System. Innov. Food Sci. Emerg. Technol. 2001, 2, 229-238.

7. Meneses, N.; Jaeger, H.; Moritz, J.; Knorr, D. Impact of Insulator Shape, Flow Rate and Electrical Parameters on Inactivation of $E$. Coli Using a Continuous co-Linear PEF System. Innov. Food Sci. Emerg. Technol. 2011, 12, 6-12.

8. Jaeger, H.; Meneses, N.; Knorr, D. Impact of PEF Treatment Inhomogeneity Such as Electric Field Distribution, Flow Characteristics and Temperature Effects on the Inactivation of E. Coli and Milk Alkaline Phosphatase. Innov. Food Sci. Emerg. Technol. 2009, 10, 470-480.

9. Álvarez, I.; Pagán, R.; Condón, S.; Raso, J. The Influence of Process Parameters for the Inactivation of Listeria Monocytogenes by Pulsed Electric Fields. Int. J. Food Microbiol. 2003, 87, 87-95

10. Jaeger, H.; Meneses, N.; Knorr, D. Model for the Differentiation of Temperature and Electric Field Effects During Thermal Assisted PEF Processing. J. Food Eng. 2010, 100, $109-118$.

11. Lindgren, M.; Aronsson, K.; Galt, S.; Ohlsson, T. Simulation of the Temperature Increase in Pulsed Electric Field (PEF) Continuous Flow Treatment Chambers. Innov. Food Sci. Emerg. Technol. 2002, 3, 233-245.

12. Saldaña, G.; Puértolas, E.; Álvarez, I.; Meneses, N.; Knorr, D.; Raso, J. Evaluation of a Static Treatment Chamber to Investigate Kinetics of Microbial Inactivation by Pulsed Electric Fields at Different Temperatures at Quasi-Isothermal Conditions. J. Food Eng. 2010, 100, 349-356.

13. Arsène, F.; Tomoyasu, T.; Bukau, B. The Heat Shock Response of Escherichia Coli. Int. J. Food Microbiol. 2000, 55 (1-3), 3-9.

14. Straus, D. B.; Walter, W. A.; Gross, C. A. The Heat Shock Response of E. Coli is Regulated by Changes in the Concentration of [Sigma]32. Nature 1987, 329 (6137), 348-351.

15. Morren, J.; Roodenburg, B.; de Haan, S. W. H. Electrochemical Reactions and Electrode Corrosion in Pulsed Electric Field (PEF) Treatment Chambers. Innov. Food Sci. Emerg. Technol. 2003, 4, 285-295.

16. Meir, A.; Rubinsky, B. Electrical Impedance Tomography of Electrolysis. PLOS ONE 2015, 10 (6), e0126332. https://doi.org/10.1371/journal.pone.0126332.

17. Meneses, N.; Jaeger, H.; Knorr, D. PH-Changes During Pulsed Electric Field Treatments—Numerical Simulation and in Situ Impact on Polyphenol Oxidase Inactivation. Innov. Food Sci. Emerg. Technol. 2011, 12, 499-504.

18. Turjanski, P.; Olaiz, N.; Maglietti, F.; Michinski, S.; Suárez, C.; Molina, F. V.; Marshall, G. The Role of pH Fronts in Reversible Electroporation. PLoS ONE 2011, 6 (4), e17303. https://doi.org/10.1371/journal.pone.0017303.

19. Golberg, A.; Belkin, M.; Rubinsky, B. Irreversible Electroporation for Microbial Control of Drugs in Solution. AAPS PharmSciTech 2009, 10 (3), 881-886. https://doi.org/ 10.1208/s12249-009-9277-3.

20. Chafai, D. E.; Mehle, A.; Tilmatine, A.; Maouche, B.; Miklavčič, D. Assessment of the Electrochemical Effects of Pulsed Electric Fields in a Biological Cell Suspension Bioelectrochemistry 2015, 106 (Pt B), 249-257.

21. Kotnik, T.; Miklavčič, D.; Mir, L. M. Cell Membrane Electro Permeabilization by Symmetrical Bipolar Rectangular Pulses: Part II Reduced Electrolytic Contamination. Bioelectrochemistry 2001, 54, 91-95.

22. Pataro, G.; Barca, G. M. J.; Donsì, G.; Ferrari, G. On the Modeling of Electrochemical Phenomena at the Electrode-Solution Interface in a PEF Treatment Chamber: Methodological Approach to Describe the Phenomenon of Metal Release. J. Food Eng. 2015, 165, 34-44.

23. Rodaite-Riseviciene, R.; Saule, R.; Snitka, V.; Saulis, G. Release of Iron lons from the Stainless Steel Anode Occurring During High-Voltage Pulses and its Consequences for Cell Electroporation Technology. IEEE Trans. Plasma Sci. 2014, 42, 249-254.

24. Roodenburg, B.; Morren, J.; Berg, H. E.; de Haan, S. W. H. Metal Release in a Stainless Steel Pulsed Electric Field (PEF) System Part II. The Treatment of Orange Juice; Related to Legislation and Treatment Chamber Lifetime. Innov. Food Sci. Emerg. Technol. 2005, 6, 337-345.

25. Pataro, G.; Falcone, M.; Donsì, G.; Ferrari, G. Metal Release from Stainless Steel Electrodes of a PEF Treatment Chamber: Effects of Electrical Parameters and Food Composition. Innov. Food Sci. Emerg. Technol. 2014, 21, 58-65.

26. Saulis, G.; Rodaite-Riseviciene, R.; Snitka, V. Increase of the Roughness of the Stainless-Steel Anode Surface due to the Exposure to High-Voltage Electric Pulses as Revealed by Atomic Force Microscopy. Bioelectrochemistry 2007, 70, 519-523.

27. Kooijmans, S. A. A.; Stremersch, S.; Braeckmans, K.; de Smedt, S. C.; Hendrix, A.; Wood, M. J. A.; Schiffelers, R. M.; Raemdonck, K.; Vader, P. Electroporation-Induced siRNA Precipitation Obscures the Efficiency of siRNA Loading into Extracellular Vesicles. J. Control. Release 2013, 172, $229-238$.

28. Góngora-Nieto, M. M.; Sepú Iveda, D. R.; Pedrow, P.; Barbosa-Cánovas, G. V.; Swanson, B. G. Food Processing by Pulsed Electric Fields: Treatment Delivery, Inactivation Level, and Regulatory Aspects. Lebensmittel-Wissenschaft Und-Technologie 2002, 35, 375-388.

29. Poo, M. In Situ Electrophoresis of Membrane Components. Annu. Rev. Biophys. Bioeng. 1981, 10, 245-276.

30. Poo, M.; Robinson, K. R. Electrophoresis of Concanavalin A Receptors Along Embryonic Muscle Cell Membrane. Nature 1977, 265 (5595), $602-605$.

31. Poo, M.; Lam, J. W.; Orida, N.; Chao, A. W. Electrophoresis and Diffusion in the Plane of the Cell Membrane. Biophys. J. 1979, 26 (1), 1-21. https://doi.org/10.1016/ S0006-3495(79)85231-5.

32. Stulen, G. Electric Field Effects on Lipid Membrane Structure. Biochim. Biophys. Acta 1981, 640 (3), 621-627.

33. Lopez, A.; Rols, M. P.; Teissie, J. 31P NMR Analysis of Membrane Phospholipid Organization in Viable, Reversibly Electropermeabilized Chinese Hamster Ovary Cells. Biochemistry 1988, 27 (4), 1222-1228.

34. Rauch, C.; Leigh, J. Theoretical Evaluation of Wall Teichoic Acids in the Cavitation-Mediated Pores Formation in Gram-Positive Bacteria Subjected to an Electric Field. Biochim Biophys. Acta 2015, 1850 (4), 595-601. https://doi.org/10.1016/j.bbagen.2014.12.004.

35. Hyuga, H.; Kinosita, K., Jr.; Wakabayashi, N. Deformation of Vesicles Under the Influence of Strong Electric Fields. Jpn. J. Appl. Phys. 1991, 30, 1141-1148.

36. Hyuga, H.; Kinosita, K., Jr.; Wakabayashi, N. Deformation of Vesicles Under the Influence of Strong Electric Fields II. Jpn. J. Appl. Phys. 1991, 30, 1333-1335. 
37. Winterhalter, M.; Helfrich, W. Deformation of Spherical Vesicles by Electric Fields. J. Colloid. Interf. Sci. 1988, 122, 583-586,

38. Harbich, W.; Helfrich, W. Alignment and Opening of Giant Lecithin Vesicles by Electric Fields. Z. Naturforsch. 1991, 34a, 133-1335.

39. Riske, K. A.; Dimova, R. Electro-Deformation and Poration of Giant Vesicles Viewed With High Temporal Resolution. Biophys. J. 2005, 88 (2), $1143-1155$.

40. Yamamoto, T.; Aranda-Espinoza, S.; Dimova, R.; Lipowsky, R. Stability of Spherical Vesicles in Electric Fields. Langmuir 2010, 26 (14), 12390-12407. https://doi.org/ 10.1021/la1011132.

41. Evans, E.; Volkmar, H.; Florian, L.; Wieslawa, R. Dynamic Tension Spectroscopy and Strength of Biomembranes. Biophys. J. 2003, 85, 2342-2350.

42. Mauroy, C.; Portet, T.; Winterhalder, M.; Bellard, E.; Blache, M. C.; Teissié, J.; Zumbusch, A.; Rols, M. P. Giant Lipid Vesicles Under Electric Field Pulses Assessed by non Invasive Imaging. Bioelectrochemistry 2012, 87, 253-259. https://doi.org/10.1016/i.bioelechem.2012.03.008.

43. Wasungu, L.; Pillet, F.; Bellard, E.; Rols, M. P.; Teissié, J. Shock Waves Associated With Electric Pulses Affect Cell Electro-Permeabilization. Bioelectrochemistry 2014, 100, 36-43. https://doi.org/10.1016/j.bioelechem.2014.06.011.

44. Roth, C. C.; Barnes, R. A., Jr.; Ibey, B. L.; Beier, H. T.; Christopher, Mimun L.; Maswadi, S. M.; Shadaram, M.; Glickman, R. D. Characterization of Pressure Transients Generated by Nanosecond Electrical Pulse (nsEP) Exposure. Sci. Rep. 2015, 5, 15063. https://doi.org/10.1038/srep15063.

45. Eynard, N.; Sixou, S.; Duran, N.; Teissie, J. Fast Kinetics Studies of Escherichia Coli Electrotransformation. Euro. J. Biochem. 1992, 209 (1), 431-436.

46. Eynard, N.; Rodriguez, F.; Trotard, J.; Teissié, J. Electrooptics Studies of Escherichia Coli Electropulsation: Orientation, Permeabilization, and Gene Transfer. Biophys. J. 1998, $75(5), 2587-2596$

47. Baloch, M. K.; Van De Ven, T. G. M. Light Scattering from Semi-Dilute Dispersions of Nonspherical Latex Particles to an Electric Field. J. Colloid. Interf. Sci. 1990, 135, 594-597.

48. Chassy, B. M.; Flickinger, J. L. Transformation of Lactobacillus Casei by Electroporation FEMS. Microbiol. Lett. 1987, 44 (2), 173-177. https://doi.org/10.1111/j.15746968.1987.tb02263.x.

49. Valič, B.; Golzio, M.; Pavlin, M.; Schatz, A.; Faurie, C.; Gabriel, B.; Teissié, J.; Rols, M. P.; Miklavčič, D. Effect of Electric Field Induced Transmembrane Potential on Spheroidal Cells: Theory and Experiment. Eur. Biophys. J. 2003, 32, 519-528.

50. Blanckaert, V.; Salles, A.; Thomas, M. L.; Teissié, J. Electroeradication of Escherichia Coli is Under the Control of the Conductance of the Pulsing. In Jarm, Buffer T., Kramar, P., Eds., In 1st World Congress on Electroporation and Pulsed Electric Fields in Biology, Medicine and Food and Environmental Technologies (WC 2015), IFMBE Proceedings 53, 10.1007/978-981-287-817-5_81; 2015; pp 367-371.

51. Teissié, J. Conductance Dynamics to Monitor and Control Cell Electropermeabilization. In Jarm, T., Kramar, P., Eds., In 1st World Congress on Electroporation and Pulsed Electric Fields in Biology, Medicine and Food and Environmental Technologies (WC 2015), IFMBE Proceedings 53; 2015; pp 67-70 https://doi.org/10.1007/978-981-287817-5_15.

52. Sixou, S.; Eynard, N.; Escoubas, J. M.; Werner, E.; Teissié, J. Optimized Conditions for Electrotransformation of Bacteria are Related to the Extent of Electropermeabilization. Biochim. Biophys. Acta 1991, 1088 (1), 135-138.

53. Sukhorukov, V. L.; Mussauer, H.; Zimmermann, U. The Effect of Electrical Deformation Forces on the Electropermeabilization of Erythrocyte Membranes in low- and HighConductivity Media. J. Membr. Biol. 1998, 163 (3), 235-245.

54. Kinosita, K., Jr.; Tsong, T. Y. Voltage-Induced Conductance in Human Erythrocyte Membranes. Biochim. Biophys. Acta 1979, 554 (2), $479-497$.

55. Fiedler, S.; Wirth, R. Transformation of Bacteria With Plasmid DNA by Electroporation. Anal. Biochem. 1988, 170, 38-44. https://doi.org/10.1016/0003-2697(88)90086-3.

56. Taketo, A. DNA Transfection of Escherichia Coli by Electroporation. Biochim. Biophys. Acta 1988, 949 (3), 318-324. https://doi.org/10.1016/0167-4781(88)90158-3.

57. Jiang, W.; Bikard, D.; Cox, D.; Zhang, F.; Marraffini, L. A. CRISPR-Assisted Editing of Bacterial Genomes. Nat. Biotechnol. 2013, 31 (3), 233-239. https://doi.org/10.1038/ nbt.2508.

58. Luchansky, J. B.; Muriana, P. M.; Klaenhammer, T. R. Application of Electroporation for Transfer of Plasmid DNA to Lactobacillus, Lactococcus, Leuconostoc, Listeria, Pediococcus, Bacillus, Staphylococcus Enterococcus and Propionibacterium. Mol. Microbiol. 1988, 2 (5), 637-646. https://doi.org/10.1111/j.1365-2958.1988.tb00072.x.

59. Su, T.; Liu, F.; Gu, P.; Jin, H.; Chang, Y.; Wang, Q.; Liang, Q.; Qi, Q. A CRISPR-Cas9 Assisted Non-Homologous End-Joining Strategy for One-Step Engineering of Bacterial Genome. Sci. Rep. 2016, 6, 37895. https://doi.org/10.1038/srep37895.

\section{Further Reading}

Raso, J., Heinz, V., Eds.; Pulsed Electric Fields Technology for the Food Industry: Fundamentals and Applications; Food Eng. Ser. Springer: Berlin, 2006. ISBN 978-0-38731053-4.

Ahmed, J., Shafi ur Rahman, M., Eds. Handbook of Food Process Design, 1st ed.; Blackwell: Hoboken, NJ, 2012; pp 1078-1106.

Chang, D. C.; Chassy, B. M.; Saunders, J. A.; Sowers, A. E. Guide to Electroporation and Electrofusion, Elsevier: Amsterdam, 1991. Paperback ISBN: 9780121680411; eBook ISBN: 9780080917276.

Miklavcic, D., Ed. Handbook of Electroporation, Springer: Berlin, 2016. ISBN 978-3-319-26779-1.

Pakhomov, A. G.; Miklavcic, D.; Markov, M. S. Advanced Electroporation Techniques in Biology and Medicine, CRC Press: Boca Raton, FL, 2010.

Nickoloff, J. A., Ed. Electroporation Protocols for Microorganisms: Methods in Molecular Biology 47, Springer: Berlin, 1995.

Eynard, N., Teissie, J., Eds. Electrotransformation of Bacteria, Springer: Berlin, 2000. https://doi.org/10.1007/978-3-662-04305-9. ISBN: 978-3-642-08593-2, 978-3-66204305-9.

\section{Relevant Websites}

www.bioelectrochemical-soc.org/.

www.odu.edu/bioelectrics/ibc.

www.pulsedpower.eu/bioelectrics/bio_index.html. 